\title{
Rapid estimation of earthquake loss based on instrumental seismic intensity: design and realization
}

\author{
Hongsheng Huang $\cdot$ Lin Chen · Gengqing Zhu • \\ Lin Wang $\cdot$ Yanzhao Lin $\cdot$ Huishan Wang
}

Received: 10 September 2012/ Accepted: 14 December 2012/Published online: 21 November 2013

(C) The Seismological Society of China, Institute of Geophysics, China Earthquake Administration, and Springer-Verlag Berlin Heidelberg 2013

\begin{abstract}
As a result of our ability to acquire large volumes of real-time earthquake observation data, coupled with increased computer performance, near real-time seismic instrument intensity can be obtained by using ground motion data observed by instruments and by using the appropriate spatial interpolation methods. By combining vulnerability study results from earthquake disaster research with earthquake disaster assessment models, we can estimate the losses caused by devastating earthquakes, in an attempt to provide more reliable information for earthquake emergency response and decision support. This paper analyzes the latest progress on the methods of rapid earthquake loss estimation at home and abroad. A new method involving seismic instrument intensity rapid reporting to estimate earthquake loss is proposed and the relevant software is developed. Finally, a case study using the $M_{\mathrm{L}} 4.9$ earthquake that occurred in Shun-chang county, Fujian Province on March 13, 2007 is given as an example of the proposed method.
\end{abstract}

Keywords Earthquake loss estimation - Seismic instrument intensity rapid report · Building vulnerability

H. Huang $(\bowtie) \cdot$ L. Chen $\cdot$ G. Zhu $\cdot$ L. Wang $\cdot$ Y. Lin ·

H. Wang

Earthquake Administration of Fujian Province, Fuzhou 350003, China

e-mail: hshuang0514@163.com

\section{Introduction}

One of the greatest challenges faced by the governments of earthquake-prone areas is to get accurate earthquake loss information, and its distribution, and utilize it to improve emergency response and provide public information services.

After construction of the 10th and 11th 5-year Plans, recent development of the Digital Seismic Monitoring Network of China and earthquake emergency commanding system was provided with many functions, such as automatic triggering by seismic events, preliminary loss estimation, decision support, command transmission, and so on. It makes sound foundation for the future development of the observation network.

However, due to technological limitations, earthquake loss estimation becomes the main challenge in the construction of an earthquake emergency command system. This is mainly for the following three reasons: First, there is usually a difference between the distribution of earthquake ground motion calculated by the seismic attenuation model, and the real distribution. Second, the vulnerability matrix of structures that reflect structural damage under different intensities needs to be improved, no matter if it is based on the earthquake engineering methods or the statistical methods of destructive earthquake cases. Third, data quality needs to be improved, which will require a long-term investment to keep the data complete and up-to-date.

The construction of high-density seismic networks, and the rapid development of information technology, makes it possible to use the earthquake observation data and the powerful computation ability of computers to evaluate earthquake disaster loss more rapidly than has previously been seen.

In the late 1990s, the TriNet Project had been carried out in Southern California, USA. It uses the state-of-art 
communication technology and data processing to realize the rapid transmission (near real-time) and sharing of seismic data. By using the data from TriNet, the ShakeMap can be quickly obtained in the 5-10 min following a seismic event. Then, the effected area and related losses can be rapidly assessed by combining the HAZUS, a loss estimation tool developed by Federal Emergency Management Agency, with the ShakeMap in the 10-20 min following the quake (Goltz et al. 1996, 1997; Goltz 2003).

In Japan, by using K-Net (Kyoshin Net, means seismic strong ground motion observation network) data, similar research has been carried out and near real-time ground motion distribution maps have been obtained. In particular, Yokohama City established the Real-time assessment of earthquake disaster in Yokohama (READY) system, which uses the dense, strong motion network consisting of 150 strong motion accelerographs on the ground surface, and nine down-hole accelerometers in the bedrock that are installed at approximately $20-60 \mathrm{~m}$ underground beneath coastal areas. The earthquake loss can be quickly estimated after 20 min after an event (Torii et al. 1998).

In Taiwan, there are two high-density digital strong ground motion observation networks operated by Central Weather Bureau. They are the Taiwan rapid earthquake information release system (TREIRS, also called as real-time digital flow output system, TRD) and the Taiwan strong ground motion instrument plan (TSMIP). The former includes 80 real-time acceleration seismographs, and the latter includes about 700 stations. By using the rich ground motion acceleration observation data obtained from these networks, the researchers in Taiwan are able to obtain high resolution, near real-time seismograms, which have yielded good results. For example, the ShakeMap of the September 21, 1999 Chi-chi earthquake and the actual loss distribution obtained by field investigation were compared (Jean et al. 2004), and they are consistent with one another (Jean et al. 2004).

As early as 2004, the authors proposed to utilize the strong ground motion observation data from earthquakes to carry out rapid earthquake loss estimation. However, the seismic stations were too sparse to calculate seismic instrument intensity at that time, and the research was not fruitful, owing to lack of satisfactory station density (Huang 2004).

During the period of the 10th 5-year plan, Fujian Province increased investment in the construction of earthquake observation stations. There are now 125 seismic stations, including strong ground motion stations and microseismic stations. Meanwhile, by using acceleration simulation technology (Jin et al. 2010), we can use microseismic stations' velocity records to simulate the acceleration, and utilize the whole network as a resource to obtain the intensity of the seismic instruments. This progress makes it possible to use seismic observation data to calculate and obtain seismic instrument intensity reports in real-time by interpolation, and, based on the seismic instrument intensity distribution, the earthquake losses can be quickly estimated.

In addition, in the period of the 9th and 10th 5-year plans, many different scales and methods of earthquake loss estimation were developed in Fujian Province. A great number of vulnerability data were obtained, and a lot of information was gathered. All of these achievements make it possible to use seismic instrument intensity to estimate earthquake loss. Although the results cannot replace actual damage investigation and loss assessment at the site of the earthquake, the ability to rapidly assess earthquake damage in near real-time makes it a valuable tool for earthquake emergency response.

\section{Methodology}

In order to obtain rapid earthquake disaster assessment results based on the data we first use real-time waveforms, the earthquake epicenter, and magnitude parameters to calculate earthquake ground motion and seismic instrument intensity. Then, by using the building loss estimation model, the property loss estimation model, the lifeline loss estimation model, the casualty estimation model, and the homeless quantity estimation model; the loss of property, number of casualties, and the quantity of the homeless people can be estimated. Figure 1 shows a flowchart of this procedure.

\subsection{Seismic instrument intensity rapid report}

Seismic instrument intensity rapid reports are derived by using seismic observation data of digital telemetry seismic networks, including magnitude, epicenter location (latitude and longitude), real-time waveform, and other information. After data processing, a seismic peak acceleration distribution can be generated. It is noted, however, that the velocity records of waveforms from microseismic stations can also be simulated into acceleration records, and

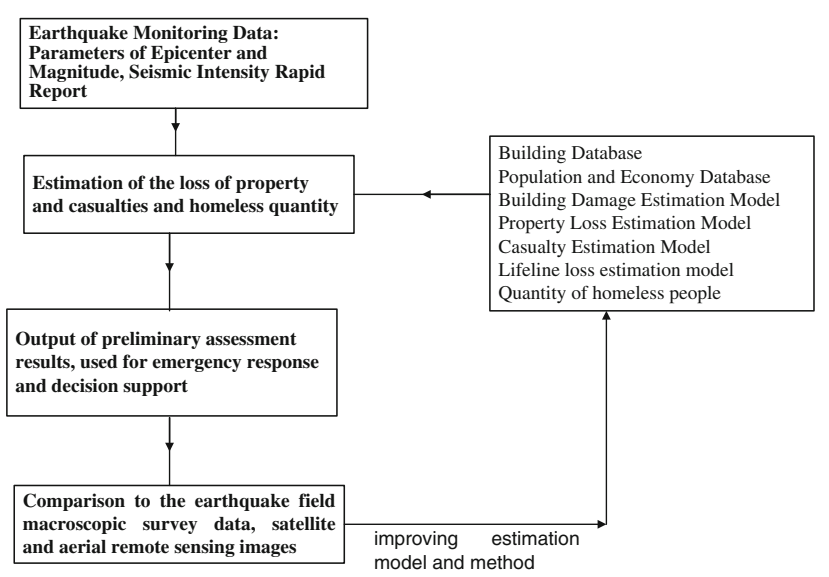

Fig. 1 Flowchart of rapid loss estimation after a destructive earthquake 
included as a source of observation data for seismic instrument intensity rapid reporting.

The monitoring area of the Fujian Seismic Network is divided into $5 \mathrm{~km}$ of the grid, and with the increasing number of seismic stations, the length of grid can be appropriately reduced to improve its accuracy. When a grid has seismic station inside, the real-time observation acceleration value can be used, including those simulated from the velocity observation value. When there is no seismic station inside the grid, the acceleration value can be obtained by an interpolation method. The principle of the interpolation method is that the space interpolation meets ground motion attenuation relationships, and its travel time is in accordance with the seismic wave propagation equation (Jin et al. 2010).

At present, we mainly use the peak acceleration, or intensity, to describe the ground motion intensity, but in the near future we will be able to use peak velocity, duration, and a combination of various ground motion parameters to express the ground motion intensity (Kramer 1996).

\subsection{Building vulnerability}

Nowadays, assessing how vulnerable buildings are to earthquake hazards is mainly based on two methods. The first is an earthquake engineering method, and the other is a statistical analysis of the past earthquake disaster data.

The typical example of the first method is the earthquake loss estimation research carried out in Fujian Province by the Fujian Earthquake Administration during the 9th and 10th 5-year-plan periods. By using a seismic engineering method, the building vulnerabilities were analyzed, and the loss ratios of different types of buildings under the different ground motion intensities (or GPA) were obtained. The advantage is that we can get the building vulnerability matrices respective to a variety of building types. But because of the complexity of earthquake destructive forces, it cannot reflect the actual building damage.

The second method is often used in macroscopic and large-scale earthquake loss estimation. If there are enough data to establish a statistical model, the results will better reflect the actual building damage. However, the actual situation is that only a few types of building structures have enough data available. Most building structure types cannot use this method to get the vulnerability matrix.

In our research, we used the statistical earthquake loss data from the 2008 Wenchun earthquake in combination with the achievements of earthquake loss estimation results from the Fujian Province during the 9th, 10th, and 11th 5-year-plan periods, in order to determine the vulnerability matrix as accurately as possible.

The basic principles and procedures are as follows: first, according to the 2008 Wenchuan earthquake statistical data, we carried out the Wenchuan earthquake vulnerability research for all different types of buildings, and the vulnerability curve and failure probability matrices of different types of buildings in the Wenchuan earthquake area were obtained. Second, by comparing vulnerability curves and failure probability matrices from the Wenchuan earthquake area with the results obtained from earthquake loss estimation research in the Fujian Province, we concluded that the vulnerability curves and failure probability matrices of buildings in the Wenchuan earthquake area were available in Fujian Province to some extent. Third, based on the results of the building research of Wenchuan earthquake area, considering its different characters to Fujian province, we put forward the regional characterization correction according to the special situation and the development of Fujian Province.

According to the results of building aseismic performance evaluation in Fujian Province, we divided building aseismic performance into five categories: good, not bad, average, bad, and worst. Then, we empirically use actual buildings damaged by the Wenchuan earthquake for analogy.

We divided the failure state of the different types of buildings under a certain intensity into five levels: no damage, slight damage, moderate damage, serious damage, and collapsed. We obtained the building loss ratio (expressed as a percentage) of different building types in different failure conditions under the different intensities, namely for the vulnerability matrix. Taking rural brick and concrete structures as an example, the vulnerability matrix in tabular form is shown in Table 1. There are different vulnerability matrices at the same intensity in Table 1, and they stand for different catalogues of aseismic performance of certain type of buildings. The top-line to bottom-line indicates good, not bad, average, bad, and worst aseismic performance, respectively. ${ }^{1}$

\subsection{Loss estimation model}

The estimation of losses and casualties follows basic loss equations (Goltz et al. 1997). In general, the following equation is used:

Damage $=E[$ Damage $\mid$ Intensity $]$

where $E[$ ] represents the expected or mean value of damage, given a particular intensity level. That is, once the intensity is known for a particular site, the appropriate loss algorithm is selected, and losses are estimated based on the observed intensity. Equation (1) is generally referred to as a loss function or algorithm.

\footnotetext{
${ }^{1}$ Earthquake Administration of FuJian Province, Technical Report on the earthquake loss rapid estimation system of Fujian Provinceprogram of 10th five-year plan of Fujian province (in Chinese).
} 
Table 1 Rural brick and concrete structure vulnerability matrix table

\begin{tabular}{|c|c|c|c|c|c|}
\hline \multirow[t]{2}{*}{ Intensity } & \multicolumn{5}{|l|}{ Failure state } \\
\hline & No damage & Slight damage & Moderate damage & Serious damage & Collapsed \\
\hline \multirow[t]{5}{*}{ VI } & 87 & 11.4 & 1.4 & 0.2 & 0 \\
\hline & 81.5 & 15.4 & 2.4 & 0.7 & 0 \\
\hline & 76 & 19.4 & 3.4 & 1.2 & 0 \\
\hline & 70.5 & 23.4 & 4.4 & 1.7 & 0 \\
\hline & 65 & 27.4 & 5.4 & 2.2 & 0 \\
\hline \multirow[t]{5}{*}{ VII } & 38.6 & 36.9 & 13 & 10.9 & 0.6 \\
\hline & 34.1 & 30.9 & 19 & 12.9 & 3.1 \\
\hline & 31.1 & 24.9 & 23.5 & 14.9 & 5.6 \\
\hline & 25.1 & 18.9 & 31 & 16.9 & 8.1 \\
\hline & 20.6 & 12.9 & 37 & 18.9 & 10.6 \\
\hline \multirow[t]{5}{*}{ VIII } & 3.5 & 5.3 & 34.9 & 37.9 & 18.4 \\
\hline & 7.5 & 10.8 & 30.4 & 33.9 & 17.4 \\
\hline & 11.5 & 16.3 & 25.9 & 29.9 & 16.4 \\
\hline & 15.5 & 21.8 & 21.5 & 25.8 & 15.4 \\
\hline & 19.5 & 27.3 & 16.9 & 21.9 & 14.4 \\
\hline \multirow[t]{5}{*}{ IX } & 0.8 & 2 & 12 & 40 & 45.2 \\
\hline & 1.8 & 5.5 & 15 & 34.5 & 43.2 \\
\hline & 2.8 & 9 & 18 & 29 & 41.2 \\
\hline & 3.8 & 12.5 & 21 & 23.5 & 39.2 \\
\hline & 4.8 & 16 & 24 & 18 & 37.2 \\
\hline \multirow[t]{5}{*}{$X$} & 0.6 & 1.1 & 7.2 & 18.4 & 72.7 \\
\hline & 1.1 & 2.6 & 8.7 & 19.9 & 67.7 \\
\hline & 1.6 & 4.1 & 10.2 & 21.4 & 62.7 \\
\hline & 2.1 & 5.6 & 11.7 & 22.9 & 57.7 \\
\hline & 2.6 & 7.1 & 13.2 & 24.4 & 52.7 \\
\hline
\end{tabular}

The numbers of casualties and homeless in the aftermath of an earthquake are affected by many factors, such as seismic intensity, the structural damage degree, the density of population of earthquake region, the number of people in an area when the earthquake occurred, the effectiveness of search and rescue activity, and the possibility self rescue and mutual rescue among others. Meanwhile, they are affected by many unpredictable and uncertain factors as well (Feng and Huang 2012).

The main factor, however, that affected the number of casualties and homeless people is the damage to buildings. Therefore, the number of casualties and people rendered homeless can be estimated on the basis of the damage of buildings, thereby providing information and allowing decisions to be made during earthquake early-warning procedures.

The following data are used in this study: earthquake disaster loss data in mainland China from 1996 to 2009, 2008 Wenchuan great earthquake loss statistical data, the $M \geq 5$ earthquake disaster loss data in mainland China from October 1949 to June 1981, and the global earthquake damage loss data from 2002. Using the regression method, the assessment model assessing the number of casualties and people rendered homeless has been concluded (Feng and Huang 2012).

Because of the great difference in quantity of casualties caused by different magnitudes of earthquake, the casualty assessment model is divided into three categories, according to magnitude: the medium-strong earthquakes $5 \leq M<6$; the strong earthquake $6 \leq M<7$; and the large earthquakes $M \geq 7$.

\subsubsection{When $M \geq 7$}

$M_{\mathrm{d} 1}=\mathrm{n}_{\mathrm{i}} \mathrm{c} \eta\left(0.0372 A_{1}+0.0149 A_{2}+0.00234 A_{3}\right)$

$M_{\mathrm{h} 1}=\mathrm{n}_{\mathrm{i}} \mathrm{c} \eta\left(0.121 A_{1}+0.0344 A_{2}+0.0134 A_{3}\right)$

where $M_{\mathrm{dl}}$ is the death toll when $M \geq 7$ (people), $M_{\mathrm{hl}}$ is the number of injured when $M \geq 7$ (people), $A_{1}$ is the area of 
clasped house $\left(\mathrm{m}^{2}\right), A_{2}$ is the area of serious damage house $\left(\mathrm{m}^{2}\right), A_{3}$ is the area of moderate damage house $\left(\mathrm{m}^{2}\right), \eta$ is the density population in the house (people $/ \mathrm{m}^{2}$ ), $c$ is the regional adjustment coefficient, and $n_{\mathrm{i}}$ is the coefficient for the time of earthquake occurrence; $n_{\mathrm{i}}=0.6$ when earthquake occurred during the day (7:00-19:00), $n_{\mathrm{i}}=1$ when earthquake occurred at night (19:00-24:00 and 0:00-7:00).

\subsubsection{When $6 \leq M<7$}

$M_{\mathrm{d} 2}=n_{\mathrm{i}} c \eta\left(0.000436 A_{1}+0.0000299 A_{2}\right)$

$M_{\mathrm{h} 2}=n_{\mathrm{i}} c \eta\left(0.163 A_{1}+0.0104 A_{2}\right)$

where $M_{\mathrm{d} 2}$ is the death toll when $6 \leq M<7$ (people), $M_{\mathrm{h} 2}$ is the number of injured when $6 \leq M<7$ (people), $A_{1}$ is the area of clasped house $\left(\mathrm{m}^{2}\right), A_{2}$ is the area of serious damage house $\left(\mathrm{m}^{2}\right), \eta$ is the density population in the house (people $\left./ \mathrm{m}^{2}\right), c$ is the regional adjustment coefficient, and $n_{\mathrm{i}}$ is the coefficient for the time of earthquake occurrence; $n_{\mathrm{i}}=0.6$ when earthquake occurred during the day (7:00-19:00), $n_{\mathrm{i}}=1$ when earthquake occurred at night (19:00-24:00 and 0:00-7:00).

\subsubsection{When $5 \leq M<6$}

$M_{\mathrm{d} 3}=0.0000002 B_{1}+0.00005847 \mathrm{~B}_{2}$

$M_{\mathrm{h} 3}=0.0001599 B_{1}+0.002795 \mathrm{~B}_{2}$

where $M_{\mathrm{d} 3}$ is the death toll when $5 \leq M<6$ (people), $M_{\mathrm{h} 3}$ is the number of injured when $5 \leq M<6$ (people), $B_{1}$ is the number of impacted in the area with seismic intensity $\mathrm{VI}$ (people), and $B_{2}$ is the number of impacted in the area with seismic intensity VII (people), The above Eqs. (2-7) were detailed in the technical report listed (see footnote 1).

\subsubsection{The estimation model of the quantity of homeless people}

It is very necessary to rapidly estimate the number of homeless in a destructive earthquake for the efforts of disaster relief, and to make emergency countermeasures. We should note that "resettled people" refer to people finding temporary residence after their original residential houses collapsed or suffered a certain degree of damage in the earthquake.

The number of homeless people can be determined as follows:

$M_{\mathrm{r}}=S-M_{\mathrm{d}}-M_{\mathrm{h}}-A_{0} \eta$

where $M_{\mathrm{r}}$ is the number of homeless (people), $S$ is the population (people), $M_{\mathrm{d}}$ is the death toll (people), $M_{\mathrm{h}}$ is the number of injured (people), $A_{0}$ is the area of non-damaged house $\left(\mathrm{m}^{2}\right)$, and $\eta$ is the density population in the house (people $/ \mathrm{m}^{2}$ ).

\section{Application example}

We take the Shun-chang $M_{\mathrm{L}} 4.9$ earthquake, which occurred in Shun-chang county, Fujian province, on March 13, 2007 as an example to show the system operation process. When the system acquires the epicenter parameters, magnitude, and seismic instrument intensity data from an earthquake, the seismic instrument intensity data are transferred to a GIS factor layer by the way of service call, and the earthquake-related losses are estimated. Finally, the evaluation results are shown in the GIS platform (Fig. 2).

Since there is no better earthquake example in Fujian province at present, and even though there are some good destructive earthquake cases in some other provinces, unfortunately, there are no seismic instrument intensity data available. The example we give here is only used to demonstrate the function of the system.

\section{Discussion and conclusions}

After the rapid development period from "the 9th 5-year plan" to "the 11th 5-year plan," digital seismic observation stations in Fujian province have a certain scale, and we have the fundamental conditions to get near real-time seismic instrument intensity by using seismic observation data. At the same time, using the vulnerability information we got in earthquake loss estimation research in the Fujian province over the past several years and Wenchun earthquake damage investigation data, we were able to develop the rapid earthquake loss estimation system to improve the accuracy of the rapid assessment of earthquake disaster and to provide more accurate and fast information to support the earthquake emergency decision making. This goal was initially achieved at the completion of this project. Yet there are many further research topics that require to be studied. In the following sections, we discuss this further research.

4.1 The comparison of rapid estimation results and the earthquake field seismic damage evaluation results

Comparing the fast estimation results with the earthquake field seismic damage evaluation results, we can further modify the estimation results, and constantly improve evaluation model and vulnerability matrix at the same time. The key to achieve this goal depends on rapidly accessing the data from earthquake disaster field. In order 


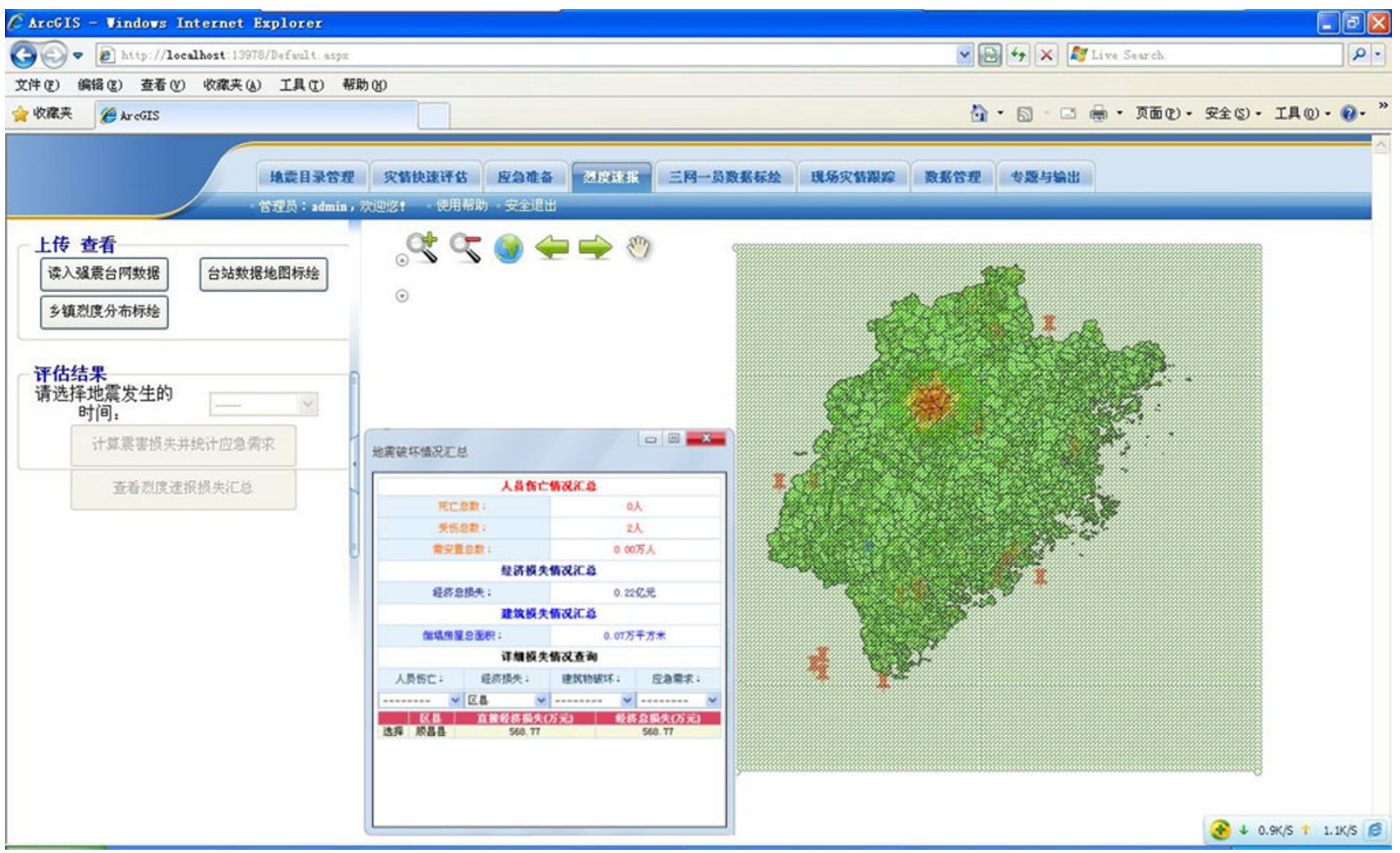

Fig. 2 The earthquake-related losses from the Shun-Chang $M_{\mathrm{L}} 4.9$ earthquake estimated by seismic instrument intensity

to realize this purpose, the research and development new earthquake field sampling investigation method and the application of satellite (or airborne) remote-sensing image in the earthquake damage rapid evaluation are the effective ways.

Improved rapid estimation result is carried out after field work team transferred a certain quantity of investigation information from the earthquake site, combining with the macroscopic investigation and theoretical calculation which is helpful to improve the earthquake losses estimation methods and good for its accuracy and rationality.

It must be emphasized that the revised estimation results are often obtained in several days or even much longer after the event, so it might be too late for the emergency response, and their main use is to provide information for decision maker of earthquake relief and reconstruction.

\subsection{Other than seismic intensity (or PGA)}

For engineering purposes, three characteristics of earthquake motion are of primary significance: the amplitude, frequency content, and duration of the motion (Kramer 1996). At present, the building vulnerability research in mainland China focuses on considering intensity and PGA factors. By comparing the relationships between PGA, PGV, and earthquake damage rate on September 21, 1999 Chi-Chi earthquake, Wu et al. (2002) suggested that the PGV is a much better index for seismic damage assessment. It is also commonly observed that relatively damageless small earthquakes can produce high PGA values near source regions, but high PGV values are only observed for large earthquakes (Wu et al. 2002).

With observation data digitization, the different observation products can be customized according to customer needs. For example, since low-frequency seismic waves are primarily responsible for damaging high-rise buildings in the cities, and high-frequency seismic waves are responsible for damage caused to house in the rural areas, we can design different seismic instrument intensity products for different objects to provide differentiation services and to improve the service quality. Therefore, we must pay more attention to PGV and even other ground motion parameters (such as duration) in the future research on vulnerability of building and structure.

In addition, we must understand how to make full use of the past earthquake damage estimation research results in Fujian province to extract earthquake vulnerability matrices (models) suited to building characteristics and the economic and social development status of Fujian province. We must also know how to search for a more 
effective interpolation method to fix the deficiency of the current seismic network density problems to a certain extent, and further advancement in this field of research is needed.

Acknowledgments This study is financially supported by National Key Technology R\&D Program Granted (No. 2009BAK55B01).

\section{References}

Feng Q, Huang HS, Chen L, Zhu GQ, Lin YZ, Wang HS (2012) Technical Report on the earthquake loss rapid estimation system of Fujian Province-program of 11th five-year plan of Fujian Province, (in Chinese)

Goltz JD (1996) Use of loss estimates by government agencies in the Northridge earthquake for response and recovery. Earthq Spectra 12(3):441-455

Goltz JD (1997) Real-time loss estimation as an emergency response decision support system: the early post-earthquake damage assessment tool (EPEDAT). Earthq Spectra 13(4):815-832

Goltz JD (2003) Applications for new real-time seismic information: the TriNet Project in Southern California. Seismol Res Lett 74(5):516-521
Huang HS (2004) A proposal of rapid earthquake loss estimation based on the data of strong ground motion observation. The collected papers of the fifth academic conference of young scientists sponsored by Fujian Association for Science and Technology (in Chinese)

Jean W-Y, Chang Y-W, Loh C-H (2004) Early estimation procedure of seismic hazard for major earthquake. Poster for Joint NCREE/JRC Workshop www.ncree.gov.tw/ncree-jrc/CD/Poster/WenYuJean. pdf

Jin X, Zhang H-C, Wei Y-X, Li J (2010) Preliminary study of near real-time interpolation calculation of ShakeMap based on seismic monitoring network's information. J Disaster Prev Reduct 26(1):2010 (in Chinese)

Kramer SL (1996) Geotechnical earthquake engineering. Prentice Hall, Upper Saddle River, pp 54-105

Torii M, Abe S, Suzuki M, Shinbo Y, Aoki T, Saito S (1998) Investigation for earthquake disaster mitigation using the dense strong motion network in Yokohama, Japan. In: Okada $\mathrm{H}$, Sasatani $\mathrm{T}$ (eds) The effects of surface geology on seismic motion. Balkema, Rotterdam

Wu Y-M, Hsiao N-C, Teng T-L, Shin T-C (2002) Near real-time seismic damage assessment of the rapid reporting system. TAO 13(3):313-324 